\title{
Investigation of the change in myocardial blood flow by perfusion CMR after revascularisation of chronically occluded coronary arteries
}

\author{
Arshad Zaman ${ }^{1 *}$, Nigel J Artis², A Crean², David L Buckley', Steven Sourbron', Sven Plein², John P Greenwood ${ }^{2}$ \\ From 2011 SCMR/Euro CMR Joint Scientific Sessions \\ Nice, France. 3-6 February 2011
}

\section{Introduction}

The perceived clinical benefits of undertaking revascularisation to coronary artery chronic total occlusions (CTO) relate to improvements in angina symptoms and prognosis ${ }^{1,2}$. Long term survival benefits from CTO revascularisation has been suggested in several large observational studies despite a significant failure rate $^{1,3}$. Data about the physiological consequences of successful opening of a CTO are limited and heterogeneous ${ }^{4}$. CMR imaging can provide quantitative information on MBF (myocardial blood flow) in this context.

\section{Purpose}

To determine changes in hyperaemic myocardial blood flow in patients undergoing revascularisation of CTO.

\section{Methods}

Twenty patients with CTO were recruited from clinical waiting lists and underwent perfusion-CMR before and after attempted CTO revascularisation on a Philips 1.5 $\mathrm{T}$ Intera system. Perfusion imaging was performed every heartbeat during the first pass using a T1-weighted fast (spoiled) GE sequence in 3 short-axis imaging planes. Stress perfusion imaging was performed using IV adenosine for 4 minutes (at $140 \mathrm{mcg} /$ $\mathrm{kg} / \mathrm{min}$ ) and $0.05 \mathrm{mmol} / \mathrm{kg}$ of gadolinium chelate via a power injector. The dynamic contrast enhanced image data were post-processed off-line using the software PMI $0.4^{5}$. Following motion correction, a circular ROI was selected in the left ventricle to measure the arterial input function. MBF maps were created by model-

${ }^{1}$ Medical Physics, Leeds, UK

Full list of author information is available at the end of the article free analysis. Two myocardial ROIs were drawn on these maps, one in the CTO territory and one in a remote normal region. MBF for these ROIs was calculated using the Fermi model ${ }^{6}$. Statistical calculations were performed using SPSS.

\section{Results}

In 16 of the 20 patients, revascularisation was successful but failed in 4 . There were highly significant improvements in adenosine-stress myocardial perfusion in the perfusion territories of the revascularised vessels. The improvements in myocardial blood flow were confined to the segments that were revascularised $(\mathrm{p}<0.001)$, whilst there were no changes seen in the remote myocardium $(\mathrm{p}=0.176)$. Figure 1 demonstrates the improvement in myocardial blood flow in the CTO versus remote regions.

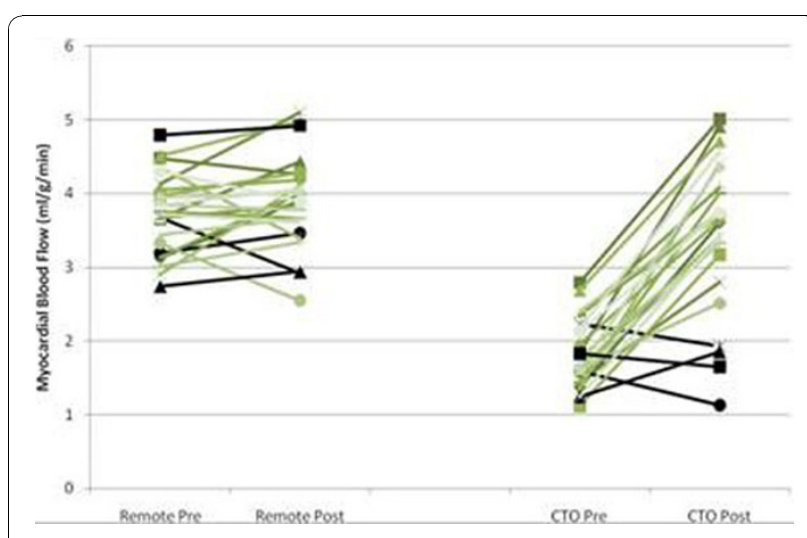

Figure 1 Graph of myocardial blood flow in the remote (normal) regions versus reperfused regions (the Black lines represent the 4 subjects that were not revascularised). 


\section{Conclusion}

Stress perfusion CMR demonstrates significant improvements in hyperaemic MBF in patients with successful revascularisation of CTO.

\section{Author details}

'Medical Physics, Leeds, UK. ${ }^{2}$ Academic Unit of Cardiovascular Medicine, Leeds, UK.

\section{Published: 2 February 2011}

\section{References}

1. Suero, et al: 2001.

2. Piscione, et al: 2005 .

3. Oliverai, et al: 2003.

4. Cheng, et al: 2008.

5. Sourbron, et al: 2009

doi:10.1186/1532-429X-13-S1-P168

Cite this article as: Zaman et al.: Investigation of the change in myocardial blood flow by perfusion CMR after revascularisation of chronically occluded coronary arteries. Journal of Cardiovascular Magnetic Resonance 2011 13(Suppl 1):P168.

Submit your next manuscript to BioMed Central and take full advantage of:

- Convenient online submission

- Thorough peer review

- No space constraints or color figure charges

- Immediate publication on acceptance

- Inclusion in PubMed, CAS, Scopus and Google Scholar

- Research which is freely available for redistribution

Submit your manuscript at www.biomedcentral.com/submit
Ciomed Central 